\title{
Acetylation of Wood Flour from Four Wood Species Grown in Nigeria Using Vinegar and Acetic Anhydride
}

\author{
Yakubu Azeh, ${ }^{1}$ Gabriel Ademola Olatunji, ${ }^{2}$ Cheku Mohammed, ${ }^{1}$ and Paul Andrew Mamza ${ }^{1,3}$ \\ ${ }^{1}$ Department of Chemistry, Ibrahim Badamasi Babangida University, Lapai, Nigeria \\ ${ }^{2}$ Department of Chemistry, University of Ilorin, Ilorin, Nigeria \\ ${ }^{3}$ Department of Chemistry, Ahmadu Bello University, Zaria, Nigeria
}

Correspondence should be addressed to Yakubu Azeh; azehyakubu@yahoo.com

Received 23 November 2012; Accepted 19 December 2012

Academic Editor: R. J. Linhardt

Copyright (C) 2013 Yakubu Azeh et al. This is an open access article distributed under the Creative Commons Attribution License, which permits unrestricted use, distribution, and reproduction in any medium, provided the original work is properly cited.

\begin{abstract}
Effect of acetylation on pretreated wood flour of four different wood species, Boabab (Adansonia digitata), Mahoganny (Daniella oliveri), African locust bean (Parkia biglobosa) and Beech wood (Gmelina arborea), had been investigated. The first batch of wood species were acetylated using acetic anhydride while the second batch were acetylated with commercial vinegar. Both experiments were conducted in the presence of varying amount of $\mathrm{CaCl}_{2}$ as catalyst and at temperature of $120^{\circ} \mathrm{C}$ for $3 \mathrm{~h}$. The success of acetylation was determined based on Weight Percent Gain for each sample treated with either chemicals used. FT-IR, a veritable tool was used for the analysis of both treated and untreated samples to further investigate the success of acetylation. The results showed the presence of important band such as carbonyl absorptions at 1743,1744,1746,1731, 1718 and $1696 \mathrm{~cm}^{-1}$ as appeared separately in the spectra of acetylated samples, confirming esterification occurred. The purpose of this work was to investigate the applicability of vinegar for acetylation of lignocellulosic fibers. Blends/composites were prepared by solution casting and their kinetics investigated in distilled water. The results indicated they could be used in outdoor applications such as, decking and packaging.
\end{abstract}

\section{Introduction}

Composites have been described as materials composed of a hard material with discontinuous reinforcement that is embedded in a weaker, continuous matrix. Where the reinforcement matrix [1] maintains the position and orientation of the reinforcement. The constituents of the composites retain their individual, physical and chemical properties. Composite give a combination of qualities that are very different from the individual constituents that constituted the composite. Several reports on thermoplastic composites have been documented. Different types of modified and unmodified natural fibers such as wood fibers and flour, kenaf fibers, sago, rice starch, cornstarch, henequen fibers, and pineapple-leaf fibers, have been used as fillers in polymer matrices $[1,2]$.

Dimensional stability and strength of unmodified wood flour polyethylene composites was reported to have improved by increased in fiber loading(s). Unmodified starch have been used to produce composites of low density polyethylene (LDPE). Composites of unmodified starch have been reported to exhibit low mechanical properties, though with improved biodegradation. The introduction of ester groups unto starch surface, manipulate its properties and support the blending mechanism [3]. Wood-Plastic composites have been described as products form by combining treated or untreated wood in the form of fiber or particles and a thermoplastic polymer such as polyethylene, polyvinyl chloride, or polypropylene [4]. Wood-plastic composites have significant applications in various fields such as construction/engineering. For wood as a construction material, its use is impaired under certain degradative agents due to its hydrophilic nature, presence of cellulose, a food substrate for microorganisms. For this reason, ecofriendly methods to improve the performance of wood are been developed. All over the world, efforts has been made to move away from toxic to nontoxic means of wood modification. 
Chemical modification of wood is a very good alternative to conventional wood preservation methods. Acetylation has received considerable attention more than any other chemical modification technique known [5]. This method not only protects wood/wood-based products against degradative agents, but also changes the hydrophilic nature of the wood components (cellulose, hemicellulose, and lignin) to hydrophobicity by increasing the acetyl contents in the polymers while decreasing their $-\mathrm{OH}$ groups. This, therefore, enhances the surface energy and interfacial interaction between acetylated wood-dust and the hydrophobic polymers. It has been reported that, for every acetyl gain, one $-\mathrm{OH}$ group is eliminated. Implying that there is a reduction in hydrogen bonding within the wood reactive polymers, this can increase the interfacial bonding of PE with the acetylated wood surface [6]. Since the surface qualities plays a significant role to satisfactory interfacial performance, we, therefore, acetylate four different wood flours of four wood species grown in Nigeria using acetic anhydride and as well investigate the feasibility to use commercially available vinegar for acetylation of cellulose in lignocellulosic materials because of its low cost, availability, and renewability. Acetylation of cellulose in wood flour was carried out in the presence of varying amounts of $\mathrm{CaCl}_{2}$ as a catalyst to manipulate its properties in order to support the blending mechanism. The objectives of this work were to investigate the feasibility of vinegar for acetylation, preparation of blends/composite, and investigation of their sorption kinetics in distilled water for application in industry.

\section{Materials and Methods}

Wood flour used was from four wood species Baobab (Adansonia digitata), mahogany (Daniella oliveri), African locust bean (Parkia biglobosa), and Beechwood (Gmelina arborea) collected from a saw mill located in the Niger state Nigeria. Reagents and chemicals used were obtained from May \& Baker, and these include commercial vinegar, acetic anhydride, $\mathrm{NaOH}$, ethanol, toluene, sulphuric acid, hypochlorite, and $\mathrm{CaCl}_{2}$. All reagents used were of analytical grade.

2.1. Soxhlet Extraction. To reduce the influence of wood extractives on the acetylation, $5 \mathrm{~g}$ of $2 \mathrm{~mm}$ size wood particles was extracted with a mixture of ethanol-toluene $(2: 1 \mathrm{v} / \mathrm{v})$ for $3 \mathrm{~h}$. After extraction, samples were rinsed with ethanol followed by hot water and then oven-dried at $105^{\circ} \mathrm{C}$ for $24 \mathrm{~h}$ to reach a constant weight. The extractible content was calculated as a percentage of oven-dried test samples.

\subsection{Sample Pretreatment by Mercerization. Mercerization of} the $2 \mathrm{~g}$ oven-dried extracted sample was mercerized using $20 \mathrm{~mL}$ of $10 \% \mathrm{NaOH}$ solution. The mixture was placed on a shaker and shaked at $75 \mathrm{rpm}$ for $1 \mathrm{~h}$. Afterwards, the sample was washed with distilled water until it was neutral. The residue was oven-dried at $105^{\circ} \mathrm{C}$ for $1 \mathrm{~h}$. The procedure was repeated for each wood flour sample.

\subsection{Chemical Modification}

2.3.1. Acetylation. Acetylation was carried out in batches. The first batch was conducted using acetic anhydride while the second batch was carried out using commercial vinegar as acetylating agents in the presence of varying amounts of $\mathrm{CaCl}_{2}$ as a catalyst. $2 \mathrm{~g}$ of oven-dried samples of wood species oven-dried at $105^{\circ} \mathrm{C}$ with a constant weight $\left(W_{\text {unt }}\right)$ were treated with the acetylating chemicals each with 0.5 and $1 \mathrm{~g} \mathrm{CaCl}_{2}$ catalyst at $120^{\circ} \mathrm{C}$ during $3 \mathrm{~h}$ refluxing. After modification, the residues were thoroughly washed with distilled water until neutral and then oven-dried for $3 \mathrm{~h}$. The extent of acetylation was calculated as weight percent gains (WPGs) based on the differences in oven-dried weight of the samples before and after modification $\left(W_{\text {unt }}\right)$ and after modification $\left(W_{\text {trt }}\right)$ according to the equation

$$
\mathrm{WPG}=\frac{M_{\mathrm{trt}}-M_{\mathrm{unt}}}{M_{\mathrm{unt}}} \times 100
$$

2.3.2. Blending Procedures. The dissolution of high-density polyethylene (packaged water sachets) follows the method described by [7]. In brief, $1 \mathrm{~g}$ pieces of nonprinted portion were placed in a reaction flask and $30 \mathrm{~mL}$ of toluene was added. The contents was placed on a hot plate at $100^{\circ} \mathrm{C}$, and a thermometer was inserted. The sachets swelled at $60^{\circ} \mathrm{C}$ and then rapidly dissolved at $80^{\circ} \mathrm{C}$ to give a clear solution. Blending of high-density polyethylene and acetylated wood flour is thus described. Into the clear solution of highdensity polyethylene sachets was introduced $0.5 / 1.0 \mathrm{~g}$ of each vinegar/acetic anhydride treated or untreated wood flour while stirring for $5 \mathrm{~min}$ and then spread on clean metal plates to form a film. The thin films formed were peeled off the metal plates to afford acetylated wood flour/polyethylene blends [2].

\subsection{Water Absorption Test of Acetylated and Untreated Blends.} Three sets of specimens were prepared. Acetylated blends and untreated blends were subjected to water absorption test. The blends were soaked for 1,2 , and $16 \mathrm{~h}$, respectively. After each immersion, the blends were removed and wiped off using filter paper and then weighed and weights were noted, using the formula

$$
\frac{H_{2}-H_{1}}{H_{1}} \times 100 \% \text {, }
$$

where $H_{1}$ = initial weight of blend before immersion in water and $H_{2}=$ weight of blend after immersion in water.

2.5. Fourier Transform Infrared Spectroscopy Analysis. The properties of acetylated and untreated samples were characterized using FT-IR, Perkin-ELMER-8400S Spectrophotometer in the range $4000 \mathrm{~cm}^{-1}$ to $400 \mathrm{~cm}^{-1}$. Samples were run using the KBr pellet technique at the National Research Institute for Chemical Technology (NARICT), Zaria, KadunaNigeria. 
TABLE 1: Assignment of the IR spectra bands of functional groups in acetylated wood flour treated with acetic anhydride.

\begin{tabular}{lc}
\hline Band position $\left(\mathrm{cm}^{-1}\right)$ & Functional group \\
\hline $3973-3352$ & $-\mathrm{OH}$ bonded stretching vibrations \\
$1746-1731$ & $\mathrm{C}=\mathrm{O}$ stretching vibrations of acetate group \\
$2938-2917$ & $\mathrm{C}-\mathrm{H}$ methyl and methylene group \\
$1373-1369$ & $\left(-\mathrm{C}-\mathrm{CH}_{3}-\right)$ in acetate group due to acetylation \\
$1285-1241$ & $\left(v_{\mathrm{C}-\mathrm{O}}\right)$ stretching band vibrations of the acetyl moieties \\
$1628-1618$ & $-\mathrm{OH}$ of absorbed water \\
$1527-1511$ & $(\mathrm{C}=\mathrm{C})$, aromatic skeletal absorption caused by lignin \\
$1044-1042$ & $\mathrm{C}-\mathrm{O}$ stretching vibrations in cellulose, hemicelluloses, and primary alcohol \\
1052 & $\mathrm{C}-\mathrm{O}$ stretching in acetyl (covalence vibration) \\
$620-603$ & $\mathrm{C}-\mathrm{H}$ out-of-plane stretching absorption of aromatic ring vibrations caused by lignin
\end{tabular}

TABLE 2: Assignment of the IR spectra bands of functional groups in acetylated wood flour treated with Vinegar based on acetic anhydride and ketene related work.

\begin{tabular}{|c|c|}
\hline Band position $\left(\mathrm{cm}^{-1}\right)$ & Functional group \\
\hline $3978-3111$ & -OH stretching (bonded) vibrations \\
\hline 1718 & $\mathrm{C}=\mathrm{O}$ stretching vibrations of acetate group \\
\hline 1696 & $\mathrm{C}=\mathrm{O}$ stretching in acetyl groups \\
\hline 2723 and 2820 & $\mathrm{C}-\mathrm{H}$ stretch of methylene in celluloses and hemicelluloses \\
\hline $2928-2904$ & $\mathrm{CH}_{3}$ symmetric stretch of methyl groups of aliphatic \\
\hline $1350-1340$ & $\left(-\mathrm{C}-\mathrm{CH}_{3}-\right)$ deformation of acetate group in cellulose and hemicelluloses \\
\hline $1254-1247$ & $\left(v_{\mathrm{C}-\mathrm{O}}\right)$ stretching band vibrations of the acetyl moieties and $(\mathrm{C}=\mathrm{O})$ deformation in the ester bond during acetylation \\
\hline $1629-1624$ & $\mathrm{C}=\mathrm{C}$ stretching of aromatic ring of syringyl in lignin \\
\hline 1654 & $\mathrm{C}=\mathrm{O}$ stretching of $(\mathrm{COOH})$ in glucuronic acid \\
\hline $1527-1509$ & $\mathrm{C}=\mathrm{C}$ Stretching of the aromatic ring caused by lignin \\
\hline $1044-1042$ & $\mathrm{C}-\mathrm{O}$ stretching vibrations in cellulose, hemicelluloses, and primary alcohol \\
\hline $1439-1428$ & $\mathrm{CH}_{2}$ deformation and stretching in cellulose, lignin, and xylan \\
\hline $625-603$ & $\mathrm{C}-\mathrm{H}$ out-of-plane stretching absorption of aromatic ring vibrations caused by lignin \\
\hline
\end{tabular}

\section{Results and Discussion}

The IR spectra of acetic anhydride or vinegar treated wood flour showing the major absorption bands are shown in Tables 1 and 2. The following strong absorption bands as reflected separately on the IR spectra of vinegar treated wood flour are characteristic absorptions of bonded $-\mathrm{OH}$, and these include 3978-3339, 3477-3375, 3426-3360, 3907-3372, 3429-3387, and $3874-3111 \mathrm{~cm}^{-1}[2,8,9]$. The following peak intensities at 3029, 3104, 3345, 3602, 3352, 3852, and $3938 \mathrm{~cm}^{-1}$ as reflected separately on the IR spectra of acetic anhydride treated wood flour are characteristic absorptions of bonded - $\mathrm{OH}$ group stretching vibrations in cellulose and hemicelluloses. Acetic anhydride or vinegar treated wood flour showed reductions in - $\mathrm{OH}$ absorption bands. The $-\mathrm{OH}$ absorption bands of untreated wood flour were predominantly detected at 4008, 4055, 4107, 4290, $4394,4413,4567,4570,4685$, and $4696 \mathrm{~cm}^{-1}$. The intensity of the $-\mathrm{OH}$ absorption bands in the treated samples decreased. This decrease in the intensity of $-\mathrm{OH}$ band is an indication that the hydroxyl group contents in wood flour were reduced during reaction. Indicating that some level of acetylation had taken place $[2,9,10]$. The presence of $-\mathrm{OH}$ absorption in vinegar/acetic anhydride treated wood flour has been attributed to hydroxyl functionalities that are not accessible to chemical reagents [11]. The band at $1746-1731 \mathrm{~cm}^{-1}$ as reflected on acetic anhydride treated wood flour is characteristic absorption of carbonyl $(\mathrm{C}=\mathrm{O}$ ester) stretching vibration of acetate group in cellulose and uronic ester in hemicelluloses. This band showed evidence of acetylation [9, 12-15]. The peak absorption increased in acetic anhydride treated samples. Indicating high level of acetyl gain as shown in Table 3. While vinegar treated samples showed this band at $1718 \mathrm{~cm}^{-1}$ and $1696 \mathrm{~cm}^{-1}$. The low level of acetylation could be attributed to low-percent acetyl content in vinegar and shorter reaction time adopted for acetylation. Since vinegar treated Baobab sample gave $11.61 \%$ (WPG) during four-hour reaction unlike the other samples who gave less than $11.61 \%$ during $3 \mathrm{~h}$ reaction as reflected in Table 3. This implies that longer reaction times are required for acetylation using vinegar. $1696 \mathrm{~cm}^{-1}$ carbonyl $(\mathrm{C}=\mathrm{O})$ absorption peak has been reported in ketene treated wood cellulose [2]. The peak here has been attributed to the low penetration of acetyl, consequently leading to lower percent gains. The absorption bands at $2723 \mathrm{~cm}^{-1}$ and $2820 \mathrm{~cm}^{-1}$ observed in vinegar treated samples have been assigned to $\mathrm{C}-\mathrm{H}$ stretching vibrations of $-\mathrm{CH}_{3}$ and $-\mathrm{CH}_{2}$ 
TABLE 3: Average weight percent gain (WPG) in vinegar and acetic anhydride treated wood flour.

\begin{tabular}{lccc}
\hline Sample & Acetic anhydride (\%) & Sample & Vinegar (\%) \\
\hline Gmelina & 17 & Gmelina & 10.8 \\
Mahogany & 12 & Mahogany & 8.5 \\
Baobab & 19 & Baobab & 11.61 \\
Locust bean & 7 & Locust bean & 10.5 \\
\hline
\end{tabular}

TABLE 4: Percent of water absorption after soaking for 1,2 and 16 hours.

\begin{tabular}{|c|c|c|c|c|c|c|c|c|}
\hline \multirow{2}{*}{$\mathrm{S} / \mathrm{N}$} & \multirow{2}{*}{ Blend sample } & \multirow{2}{*}{ Dry weight (g) } & \multicolumn{3}{|c|}{ Weight after soaking/h } & \multicolumn{3}{|c|}{ Percentage of water absorption (\%)/h } \\
\hline & & & $1 \mathrm{~h}$ & $2 \mathrm{~h}$ & $16 \mathrm{~h}$ & $1 \mathrm{~h}$ & $2 \mathrm{~h}$ & $16 \mathrm{~h}$ \\
\hline 1 & $\begin{array}{l}\text { Acetic anhydride treated } \\
\text { blends }\end{array}$ & 1.00 & 1.08 & 1.16 & 1.38 & 8 & 16 & 38 \\
\hline 2 & $\begin{array}{c}\text { Acetic anhydride untreated } \\
\text { blends }\end{array}$ & 1.00 & 1.34 & 1.39 & 1.49 & 34 & 39 & 49 \\
\hline \multirow{2}{*}{3} & Untreated blends & 1.00 & & & 2.70 & & & 70 \\
\hline & Vinegar treated blends & 1.00 & & & 1.52 & & & 52 \\
\hline
\end{tabular}

groups in cellulose and hemicelluloses $[2,15]$. The presence of absorption peaks at both $2938-2091 \mathrm{~cm}^{-1}$ reflected on acetic anhydride and $2928-2904 \mathrm{~cm}^{-1}$ in vinegar treated samples has been assigned to asymmetric stretching vibration of aliphatic $-\mathrm{CH}_{3}$ group which is evidence of acetylation $[2,8$, $12,16]$. The small bands at $1628-1618$ and $1629-1624 \mathrm{~cm}^{-1}$ in acetic anhydride or vinegar treated samples are assigned to adsorbed water, $\beta$-glycosidic linkages (ether $-\mathrm{C}-\mathrm{O}-\mathrm{C}-$ ) in the cellulose chain or sugar units or could be due to aromatic ring $(C=C)$ vibrations in lignin (syringyl) [2, 9-12]. The absorption bands at $1527-1509 \mathrm{~cm}^{-1}$ are characteristic to absorption of aromatic $(\mathrm{C}=\mathrm{C})$ stretching vibrations caused by lignin (guaiacyl) [2,8-12]. This suggests the presence of lignin $[9,11]$. The bands at $1439-1428 \mathrm{~cm}^{-1}$ are due to $\mathrm{C}-\mathrm{H}$ deformations and bending vibrations of $-\mathrm{CH}_{2}$ (methylene) in cellulose and hemicelluloses [2, 14, 15, 17, 18]. These bands were not found in acetic anhydride treated wood flour. The reason could be that longer reaction time adopted led to product (cellulose/hemicelluloses) degradation and subsequently their extraction by acetylating chemical occurred and was probably washed alongside with the byproducts. An important band which showed that some level of acetylation was achieved by the two reagents used for acetylation was observed at $1330-1373 \mathrm{~cm}^{-1}$ for acetic anhydride and 1340-1348 for vinegar. This important band was attributed to aliphatic $\mathrm{C}-\mathrm{H}$ deformation/bending vibration of $-\mathrm{CH}_{3}$ in the acetyl groups and this is evidence of the formation of ester bond due to acetylation in cellulose and hemicelluloses $[2,9,10,13]$. This absorption peak was missing in the control samples. A prominent absorption band which further gave evidence of acetylation appeared at $1285-1242 \mathrm{~cm}^{-1}$ for acetic anhydride while $1254-1247 \mathrm{~cm}^{-1}$ peak absorption was detected for vinegar as alternative acetylation agent. This band has been assigned for the stretching of $\mathrm{C}-\mathrm{O}$ and the deformation of $\mathrm{C}=\mathrm{O}$ in the acetate bond formed during acetylation in xylan and lignin $[8,9,13,15]$. The absence of absorption band at $1800-1760 \mathrm{~cm}^{-1}$ in all the spectra of acetic anhydride treated samples was an indication that the acetylated products were free of unreacted acetic anhydride, implying that the reagent was used up during the reaction, while the absence of absorption peak at $1700 \mathrm{~cm}^{-1}$ in all spectra is evidence of the absence of unreacted carboxylic acid in vinegar treated samples and as byproducts in acetic anhydride treated wood flour, respectively. The bands at $1044-1042 \mathrm{~cm}^{-1}$ are assigned to $\mathrm{C}-\mathrm{O}$ stretching vibrations in cellulose, hemicelluloses, and that of primary alcohol [2, $9,10,12]$. The medium band at $1052 \mathrm{~cm}^{-1}$ ascribed to $\mathrm{C}-\mathrm{O}$ stretching vibration of the acetyl group in acetate $[2,12,14]$ is evidence of acetylation.

3.1. Water Absorption Kinetics of Acetylated and Control Wood Flour Samples. Three sets of specimens were prepared, as shown in Table 4. Blends prepared from acetylated wood flour were flexible, brittle, and very smooth and absorbed less water compared to untreated blends which were coarse with rough surface. The modification of fiber surface really helps to manipulate its properties and supports the blending mechanism as was observed on blends made from treated wood flour. It has been established that when the accessible hydroxyl groups in the cell wall polymers have been substituted by acetyl group, reduction in water and moisture sorption are observed, and this depends on the level of acetylation too. The results also showed that water absorption of blends is dependent on fibers in the matrix. It is expected that the sorption rate for $16 \mathrm{~h}$ soaking duration should give about 16 times the results obtained for $1 / 2 \mathrm{~h}$ soaking periods. However, this was not observed, indicating that the fibers in the polymer matrix have reached their saturation point and thereby cannot absorb much water molecules. Acetylated blends reached the fiber saturation point faster compared to untreated blends as indicated by the percent water uptake/sorption rate in Table 4 . This is attributed to the modification of the hydrophilic fiber surface by acetyl 


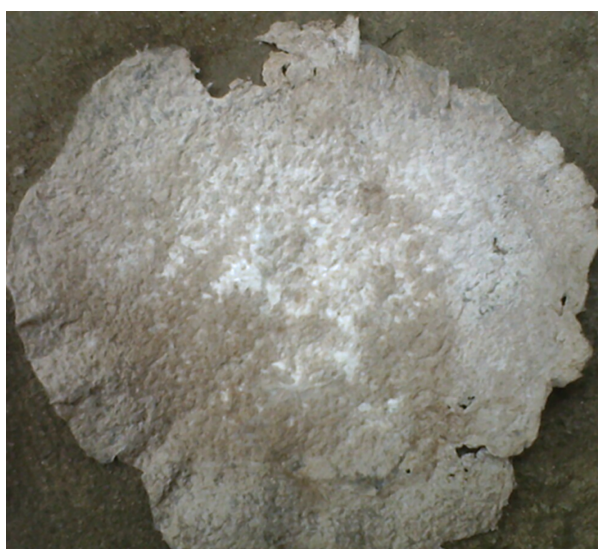

(a)

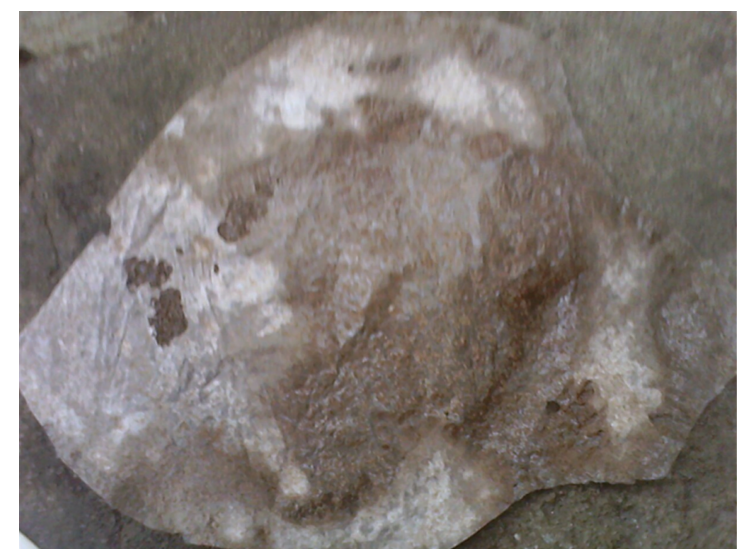

(b)

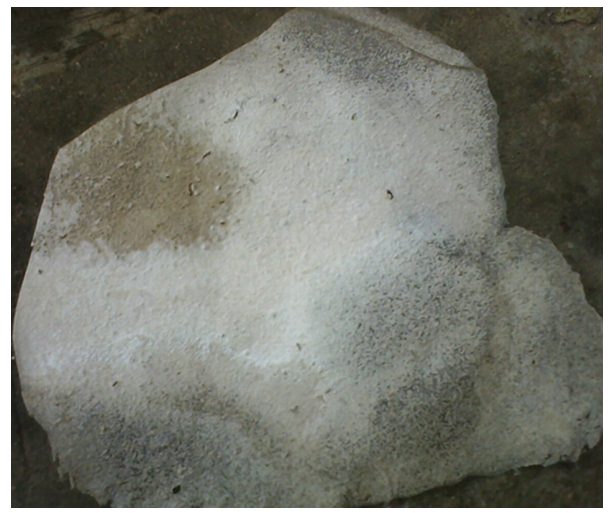

(c)

Figure 1: (a) photographic plate of acetylated blend ( $1 \mathrm{~g}$ wood flour $1 \mathrm{~g}$ polyethylene loading), (b) photographic plate of untreated blend $(0.5 \mathrm{~g}$ wood flour $/ \mathrm{g}$ polyethylene loading), and (c) photographic plate of acetylated blends $(0.5 \mathrm{~g}$ wood flour $/ 1 \mathrm{~g}$ polyethylene loading).

moieties and subsequent hydrophobicity improvement of fiber surface which allowed for proper interfacial bonding with polyethylene.

\subsection{Results of the Formation of Blends. Blends obtained from} the incorporation of acetylated wood flour with polyethylene were flexible and had smooth surface (Figures 1(a) and 1(b)). These blends were easily peeled off the film forming plate while those obtained from untreated wood flour were porous, coarse, and difficult to peel off from the film forming plate. For this reason, blends had rough surface (Figure 1(c)). Poor blend formation exhibited by untreated wood flour could be attributed to facial differences between the two materials-hydrophilic biopolymers in wood flour and the hydrophobic polyethylene, causing very poor interfacial interaction between the materials [2]. Treated wood flour resulted in the formation of flexible blends with smooth surface after incorporation and solution casting on metal plates. The properties exhibited by these blends was an indication that acetylation using vinegar and acetic anhydride successfully transformed accessible hydrophilic hydroxyl surfaces of the biopolymers in wood flour to hydrophobic surface (acetyls) which causes proper interfacial interaction with polyethylene as reported by $[2,19,20]$.

\section{Conclusion}

In this work we have been able to carry out acetylation of cellulose in wood flour using vinegar successfully. Results of the kinetic studies of blends indicated that treated blends had lower water sorption than untreated blends, implying that treated blends had lower hygroscopic surface with a high hydrophobic energy surface that facilitated its interaction with polyethylene during the blending process, while untreated blends had high water sorption, due to the presence of accessible hydrophilic hydroxyl groups in cellulose and other biopolymers in wood which allowed for strong formation of hydrogen bonds with water molecules. Treated wood flour blends could be very useful in outdoor applications such as decking and packaging.

\section{References}

[1] A. G. Supri and B. Y. Lim, "Effect of treated and untreated filler loading on the mechanical, morphological, and water absorption properties of water hyacinth fibers-low density polyethylene composites," Journal of Physical Science, vol. 20, no. 2, pp. 85-96, 2009.

[2] A. Yakubu, G. A. Olatunji, O. Sunday, and A. Olubunmi, "Ketene acetylated wood cellulose for industrial applications 
in wood-base and polymer industry," Journal of Environmental Science and Technology, vol. 5, no. 3, pp. 168-176, 2012.

[3] K. Sriroth, R. Chollakup, K. Piyachomkwan, and C. G. Oates, "Biodegradable Plastics from Cassava Starch in Thailand," Department of Biotechnology, Kasetsart University, Bangkok, Thailand.

[4] B. K. Segerholm, R. E. Ibach, and M. E. P. Walinder, "Moisture Sorption of artificially aged wood-plastic composite," BioResources, vol. 7, no. 1, pp. 1283-1293, 2012.

[5] R. M. Rowell, R. Simonson, S. Hess, D. V. Plackett, and E. Dunningham, "Acetyl distribution in acetylated whole wood and reactivity of isolated wood cell wall components to acetic anhydride," Wood Fibre Science, vol. 26, no. 1, p. 11, 1994.

[6] C. R. Frihart, R. Brandon, and R. E. Ibach, "Selectivity of bonding for modified wood. USDA forest service, forest products laboratory," in Proceedings of the 27th Annual Meeting of the Adhesion Society, Inco, From Molecules and Mechanic to Optimization and Design of Adhesive Joints, pp. 15329-18332, Adhesion Society, Madison, Wis, USA, 2004.

[7] S. A. Abdulkareem and B. Garba, "Novel application of polymer dissolution technique," Nigerian Journal of Pure and Applied Science, vol. 20, pp. 1799-1485, 2005.

[8] V. M. Tuong and J. Li, "Effect of heat treatment on the change in color and dimensional stability of acacia hybrid wood," BioResources, vol. 5, no. 2, pp. 1257-1267, 2010.

[9] B. Mohebby, "Application of ATR infrared spectroscopy in wood acetylation," Journal of Agricultural Science and Technology, vol. 10, no. 3, pp. 253-259, 2008.

[10] R. Bodîrlău and C. A. Teacă, "Fourier transform infrared spectroscopy and thermal analysis of lignocellulose fillers treated with organic anhydrides," Romanian Journal in Physics, vol. 54, no. 1-2, pp. 93-104, 2009.

[11] A. S. H. Callum, How does the chemical modification of wood provide protection against decay fungi, school of agriculture and forest science, Presentation for COST E22, University of Wales Bangor, 2002.

[12] M. Nasar, A. Emam, M. Sultan, and A. A. Abdel-Hakim, "Optimization of characterization of sugar cane bagasse liquefaction process," Indian Journal of Science and Technology, vol. 13, no. 12, pp. 207-212, 2010.

[13] Y. Indrayan, S. Yusuf, Y. S. Hadi, D. Nandika, and R. E. Ibach, "Dry wood termite resistance of Acetylated and Polymerized Tributyltin Acrylate (TBTA) indonesian and USA wood," in Proceedings of the 3rd International Wood Science Symposium, Core University Program in the Field of Wood Science, November 2000 .

[14] R. T. Morrison and R. N. Boyd, Organic Chemistry, 6th edition, 1961.

[15] M. O. Adebajo and R. L. Frost, "Infrared and ${ }^{13} \mathrm{C}$ MAS nuclear magnetic resonance spectroscopic study of acetylation of cotton," Spectrochimica Acta A, vol. 60, no. 1-2, pp. 449-453, 2004.

[16] N. S. Cetin and N. Ozmen, "Acetylation of wood components and fourier transform infra-red spectroscopy studies," African Journal of Biotechnology, vol. 10, no. 16, pp. 3091-3096, 2011.

[17] A. Sandak, J. Sandak, W. Pradzynski, M. Zborowska, and M. Negri, "Near infrared spectroscopy as a tool for characterization of wood surface," Folia Forestalia Polonica, vol. 40, pp. 31-40, 2009.

[18] P. Sikorski, M. Wada, L. Heux, H. Shintani, and B. T. Stokke, "Crystal structure of cellulose triacetate I," Macromolecules, vol. 37, no. 12, pp. 4547-4553, 2004.
[19] J. George, S. S. Bhagawan, and S. Thomas, "Effects of environment on the properties of low-density polyethylene composites reinforced with pineapple-leaf fibre," Composites Science and Technology, vol. 58, no. 9, pp. 1471-1485, 1998.

[20] Y. Azeh, G. A. Olatunji, and P. A. Mamza, "Scanning electron microscopy and kinetic studies of ketene-acetylated wood/cellulose high-density polyethylene blends," International Journal of Carbohydrate Chemistry, vol. 2012, Article ID 456491, 7 pages, 2012. 

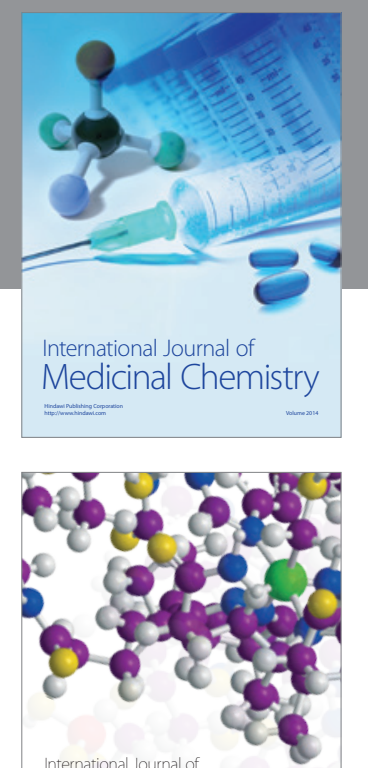

\section{Carbohydrate} Chemistry

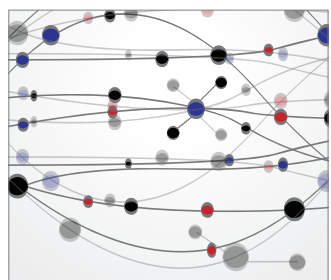

The Scientific World Journal
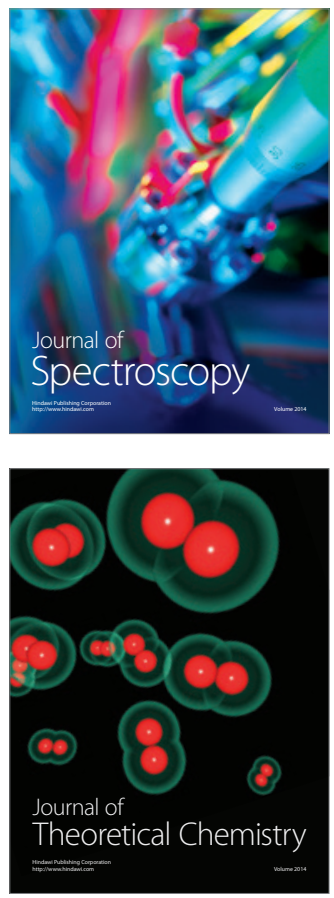
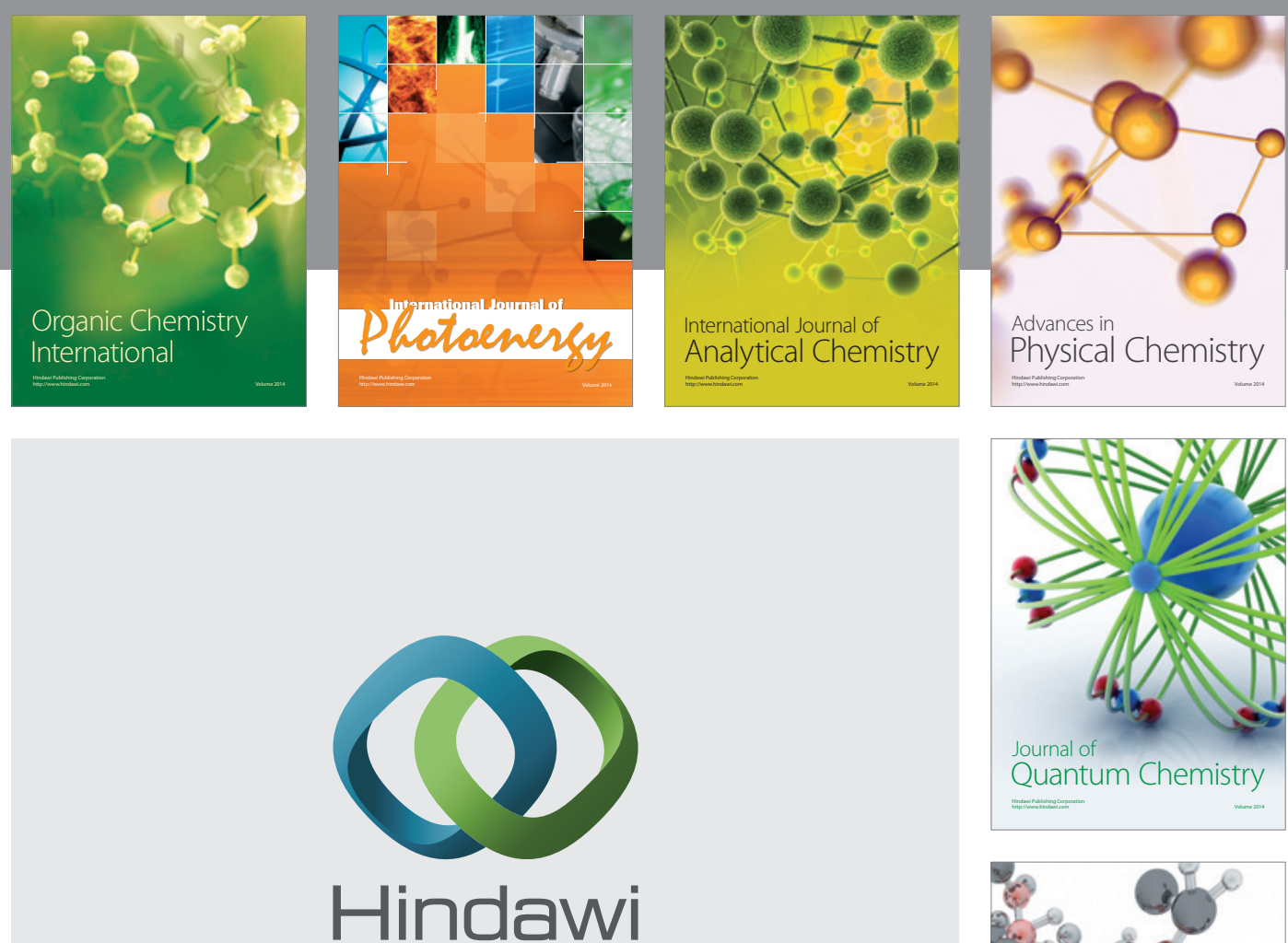

Submit your manuscripts at

http://www.hindawi.com

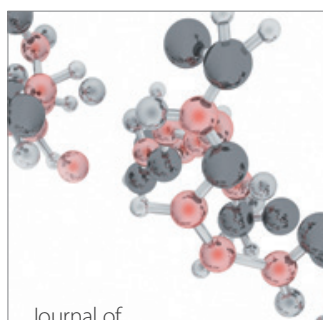

Analytical Methods

in Chemistry

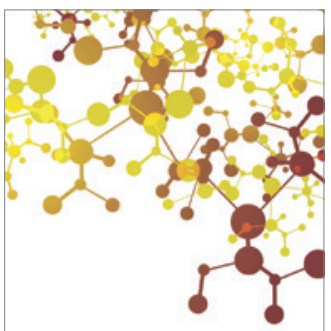

Journal of

Applied Chemistry

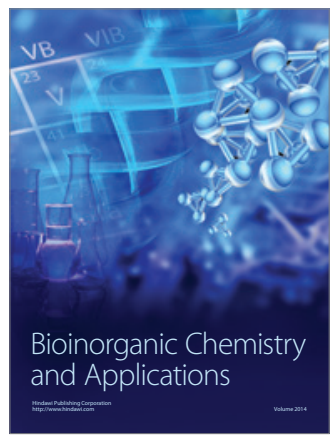

Inorganic Chemistry
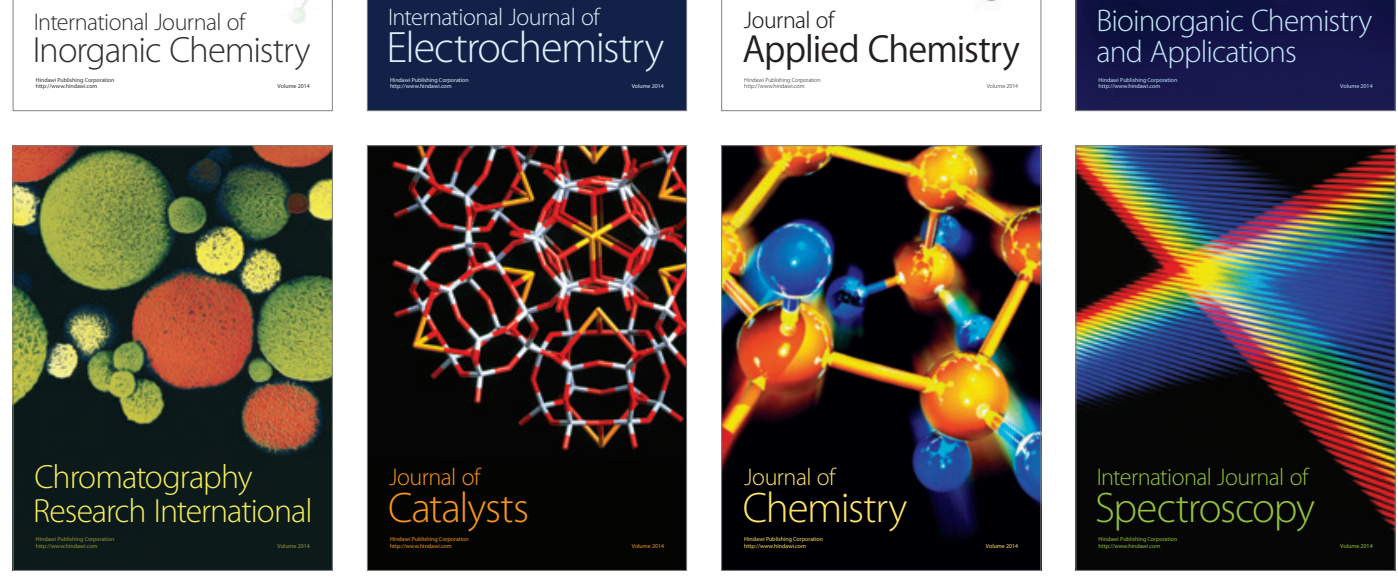